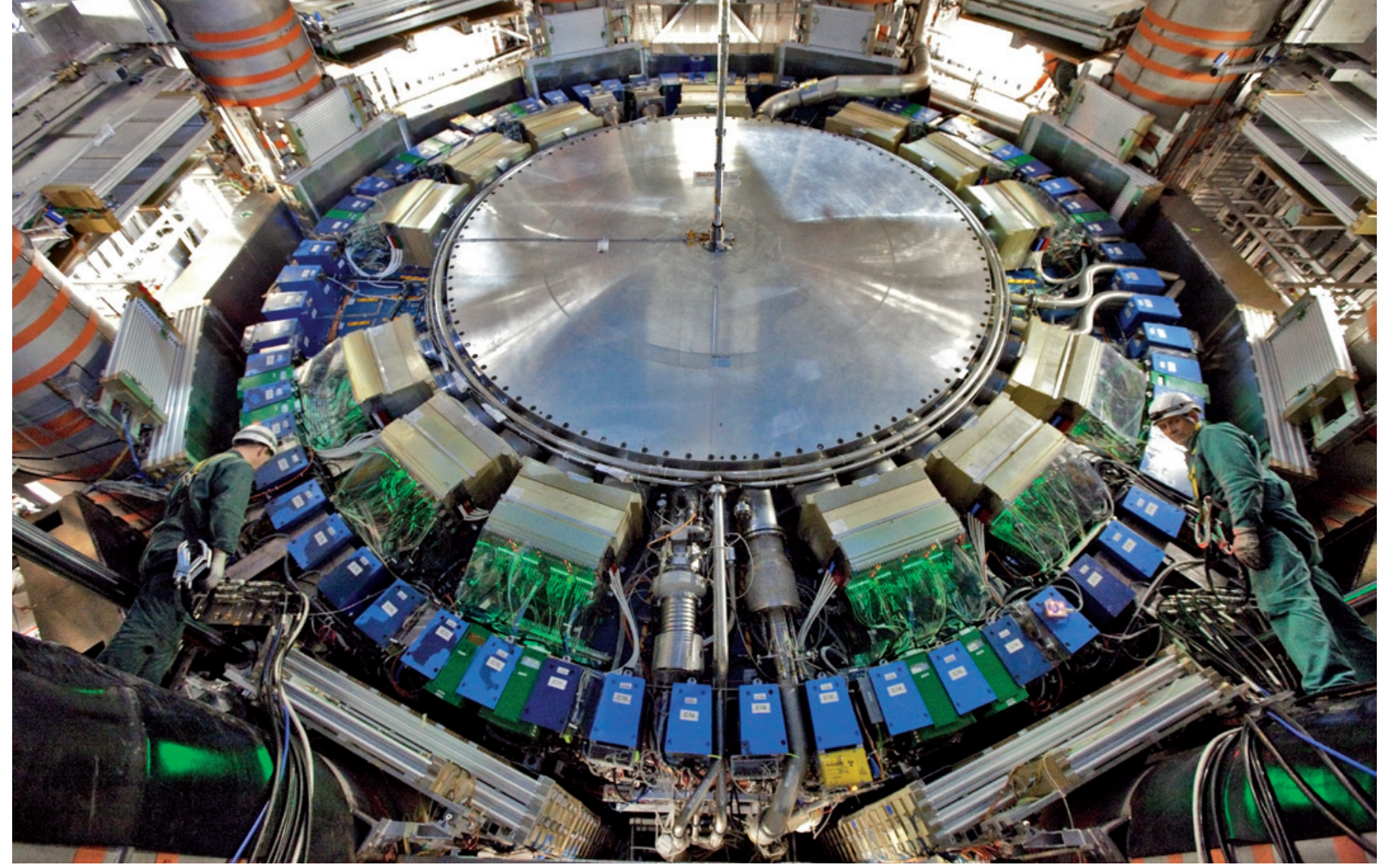

The ATLAS experiment at the Large Hadron Collider: jumping at shadows?

PARTICLE PHYSICS

\title{
The collider that cried 'Higgs'
}

\section{Data leaks from particle hunters raise questions about scientific trust.}

\section{BY GEOFF BRUMFIEL}

$\mathrm{I}$ $\mathrm{n}$ the era of WikiLeaks and Twitter, can anyone keep a secret? Governments have

learned that, all too often, the answer is no. Now, as teams of particle physicists close in on one of their biggest targets in decades, they too are struggling to keep confidential data under wraps.

In late April, leaked results from the Large Hadron Collider (LHC), the world's largest particle accelerator, seemed to show a preliminary signal of the Higgs boson. The particle is the LHC's highest-profile quarry, and would provide evidence of a theoretical mechanism that gives other particles their mass. A fresh analysis published this week has debunked the claim, but researchers are bracing themselves for a string of other false alarms to appear on blogs over the coming months.

Future leaks are "inevitable", says James Gillies, a spokesman for CERN, the European particle-physics laboratory near Geneva, Switzerland, where the LHC is housed. Proof of the Higgs' existence will not arrive as a bolt from the blue - instead, it will emerge slowly from weeks or months of data analysis, allowing ample time for each tantalizing step to be documented on blogs.
Rumours about particle discoveries are as old as the field itself, but the ease of communicating tentative finds via the Internet means that particle hunters' first clues and false starts are now being discussed on the global stage. This raises broader questions for a discipline that employs thousands of scientists to search for a handful of discoveries worthy of a Nobel prize. With the stakes so high, can preliminary results be kept secret? Should leakers or bloggers be punished for making early findings public? Above all, says Adam Falkowski, a blogger and theorist at the University of ParisSouth: "Is this bad, or not?"

The trouble began shortly after 6:45 p.m. Geneva time on 21 April, when someone posted an internal communication from the LHC's ATLAS particle detector to the popular blog 'Not Even Wrong' (go.nature.com/q55vdu). The note purported to show preliminary evidence for $\gamma$-rays from a decaying Higgs particle with a mass of about 115 gigaelectronvolts, some 115 times heavier than a proton. The number was familiar to many CERN physicists, who had seen hints of the Higgs at that mass in a previous accelerator, the Large Electron-Positron Collider.

\section{$\rightarrow$ NATURE.COM}

For Nature's special on the LHC see: www.nature.com/lhc
"Higgs? That looks very, very interesting!" wrote Peter Woit, a mathematician at Columbia University in New York City who runs Not Even Wrong. Anonymous physicists working at CERN quickly confirmed in the blog's comments thread that the data were genuine, but said questions remained about the analysis.

News of the document spread first to other blogs, then to science publications, and finally to the mainstream media. But as the news gathered momentum, it became clear to ATLAS researchers that it was a false alarm. By 24 April, Jonathan Butterworth, a physicist at University College London who works on ATLAS, was looking sheepish on British television news. "What's happened here is some people have spent four nights without sleep and got rather overexcited," he explained.

"I was surprised by the level of interest," Butterworth told Nature last week. He is relaxed about the leak, seeing it as an opportunity to discuss scientific process with the public. But others in the collaboration are less pleased. "It got me quite angry," says Gordon Watts, an ATLAS physicist at the University of Washington in Seattle. Watts says that the leak forced many in the group to spend their Easter holiday scrutinizing the new result. An official ATLAS analysis refuting the claim appeared on 
8 May (go.nature.com/zdzlji), but has not yet been widely reported in the mainstream media.

Finding out who posted the document, and why, may be impossible. On Not Even Wrong, some accused the lead author on the internal communication, physicist Sau Lan Wu of the University of Wisconsin, Madison, of seeking Higgs glory. She flatly denies that she had anything to do with the leak. "It's absolutely not from me or my group," she says. "I have never gone to a blog." Other commenters suggest that the post was actually an attempt to make Wu look bad: ATLAS explicitly prohibits its collaborators from publicly distributing or discussing internal documents or results before formal publication.

Woit says that he cannot trace the Internet address of the anonymous leaker. Even if he could, he says, "I just don't see an argument that I should be enforcing ATLAS's privacy policies".

\section{FLOOD OF LEAKS}

Perhaps inevitably, the leak was soon followed by a counter-leak. On 4 May, New Scientist magazine reported that ATLAS's main rival, the Compact Muon Solenoid (CMS) detector, had seen no evidence of the earlier leaked signal. Guido Tonelli, the spokesman for the CMS group, says that the report was probably based on slides from a presentation made a few days earlier.

Tonelli says that even if he found out who leaked the CMS data, he would do little more than talk to them about the issue. $\mathrm{He}$ acknowledges that future leaks are probably unavoidable. All 3,000 members of the CMS collaboration must have access to the data, both out of fairness and to ensure the accuracy of new findings. "I might be able to reach an efficiency of $99.9 \%$ in convincing the collaboration" to obey the rules, Tonelli says. "But three people are still enough to create a leak."

Others are divided over just how damaging the leaks are. "I don't really see damage; I see more inconvenience," says Falkowski. He believes that the press and public were quick to recognize that the leak was not an official finding. Watts nevertheless feels that it may have damaged the reputation of the collaboration and the field. "It's a credibility thing in the end," he says.

The debates, like the leaks, are sure to continue. Many physicists hope to find the Higgs hiding at around 115-130 gigaelectronvolts, where its signal can be confused with those from other particle decays. As the LHC explores that energy range, the uncertain data will mean plenty of false alarms. And as Butterworth tweeted to his followers: "If u get excited by unreviewed results leaked in breach of confidence you'll have a distracting few months." -

\section{Costs to keep ocean drilling ship in port}

\section{BY NICOLA JONES}

A $\mathrm{n}$ international effort to explore the little-known depths below the ocean floor is heading into choppy waters. Last week, the US branch of the 24-nation Integrated Ocean Drilling Program (IODP) received guidance on its budget allocation from the US National Science Foundation, one of the project's two main funders (the other being the Japan Agency for Marine-Earth Science and Technology). No cuts are anticipated to the US share of the project's budget, but a rise in fuel costs of more than $30 \%$ since the end of 2010 means that in the 2012 fiscal year the US drilling ship the JOIDES Resolution is expected to be at sea for only six months. It needs eight months to complete its four scheduled expeditions, so one project - to drill into the tectonic area off the southern coast of Alaska next summer - has been postponed.

In an open letter to colleagues last week, David Divins, director of ocean drilling programmes at the Consortium for Ocean Leadership in Washington DC, which helps to run the US component of the IODP, wrote, "I am extremely troubled by this news and the implications for the future of scientific ocean drilling."

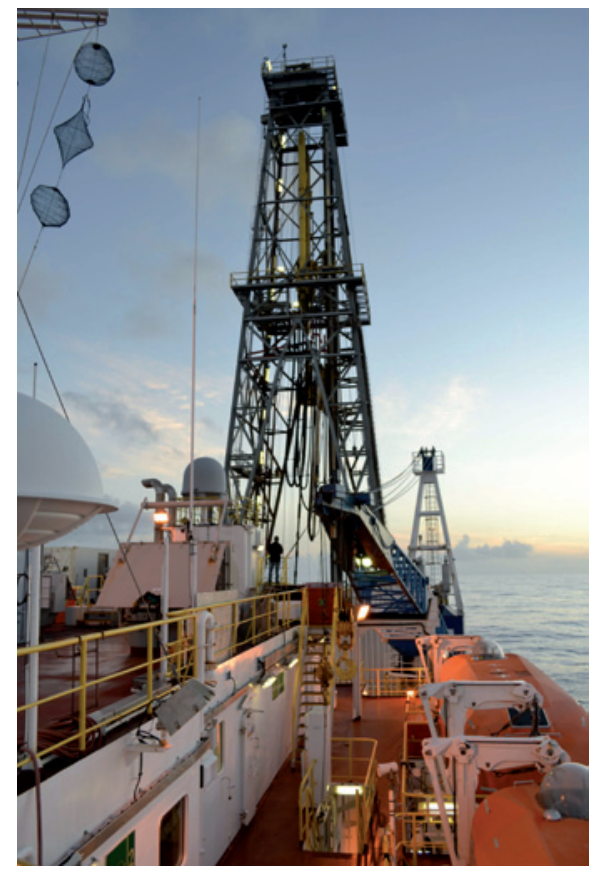

The JOIDES Resolution will spend less time at sea.
News of the vessel's scaled-back season comes just as the IODP sets its scientific goals for its next ten years. The plan is expected to be finalized this month and released in June. It highlights an ongoing emphasis on the studies of geophysics and past climates that has dominated the programme's initial ten-year mandate, which runs until 2013. "Everything we know about climate older than a million years we know from the ocean drilling programme," says Maureen Raymo, chair of the IODP's main science evaluation committee.

The next phase will also up the emphasis on studies of deep biology, and will include more efforts to install instruments in boreholes to conduct real-time experiments, rather than simply pulling up cores. And this month, scientists will be meeting in Tokyo to discuss the possibility of drilling into the fault line of the great earthquake that hit Japan in March. If they can do so within the next two years, they should be able to detect the heat generated by the slip, a clue to energy transfer during quakes.

But logistical challenges have hobbled the IODP in the past. The JOIDES Resolution was out of action for nearly three years for refurbishments that took much longer than anticipated. A new Japanese vessel capable of drilling to extreme depths, the Chikyu, has done only about 14 months of active science service since mid-2007. It was also damaged by Japan's recent tsunami, causing the cancellation of one expedition.

As a result, and in the face of serious technological challenges, the IODP has been slow to meet its original objectives. Only two expeditions have been launched specifically to study the biosphere deep beneath the sea floor, a key goal. Meanwhile, just one deep core has been retrieved from the Arctic, another major target, and investigators are behind schedule on drilling into a subduction zone - where an oceanic plate slides beneath a continental one - to study earthquake mechanisms.

Ongoing battles over US government spending have some in the drilling community concerned that the programme's cost will make it a tough sell going forwards. Divins estimates that, in total, the four expeditions originally planned for the 2012 financial year would have cost about US\$70 million. "We have to make a compelling case to keep this ship out there," says Raymo. 